\title{
Relationship between inpatient satisfaction and the quality of surgery
}

\author{
Rongyu Shang ${ }^{1}$, Duan Wang ${ }^{2}$, Huifen $\mathrm{Cai}^{3}$, Jiafei Chen ${ }^{4}$, Lin $\mathrm{Lv}^{5}$, Chunji Huang ${ }^{6}$ \\ ${ }^{1}$ Department of Medical Education, School of Basic Medicine, Army Medical University, Chongqing, China; ${ }^{2}$ Department of Cardiology, The Third \\ Affiliated Hospital of Chongqing Medical University, Chongqing, China; ${ }^{3}$ Department of Obstetrics and Gynecology, The First Affiliated Hospital \\ of Army Medical University, Chongqing, China; ${ }^{4}$ Department of Radiology, The First Affiliated Hospital of Army Medical University, Chongqing, \\ China; ${ }^{5}$ Department of Infection Control, The First Affiliated Hospital of Army Medical University, Chongqing, China; ${ }^{6}$ Army Medical University, \\ Chongqing, China \\ Contributions: (I) Conception and design: All authors; (II) Administrative support: All authors; (III) Provision of study materials or patients: All \\ authors; (IV) Collection and assembly of data: All authors; (V) Data analysis and interpretation: All authors; (VI) Manuscript writing: All authors; (VII) \\ Final approval of manuscript: All authors. \\ Correspondence to: Chunji Huang. Army Medical University, No. 30 Gaotanyan Main Street, Shapingba District, Chongqing 400038, China. \\ Email: yxjy_wz@163.com.
}

Background This study sought to investigate the correlation between inpatient satisfaction and surgical quality evaluation indicators, and explore the factors affecting inpatient satisfaction.

Methods: A total of 5,000 inpatients who underwent surgery at 10 tertiary. A hospital in Chongqing were randomly selected and asked to complete an inpatient satisfaction questionnaire developed by our team in a previous study. A logistic regression was undertaken to analyze the factors affecting inpatient satisfaction, and the relationship between inpatient satisfaction and evaluation indicators of surgical quality.

Results: The overall satisfaction level of inpatients undergoing surgery was high. Specifically, the satisfaction level was $88.7 \%$, and the dissatisfaction level was $11.3 \%$. A univariate analysis showed that age, marital status, education level, monthly family income, the source of medical costs, the average length of the hospital stay, first hospitalization or not, doctor-patient communication, the quality of surgery, service attitude, 30-day postoperative mortality, major and minor complications, the rescue failure rate, readmission, and the incision infection rate affected the patient satisfaction, and the difference between satisfied and dissatisfied patients in each group was statistically significant (all $\mathrm{P}=0.000$ ). The results of the logistic regression analysis showed that the factors related to the satisfaction of surgical quality indicators were postoperative 30-day mortality, major and minor complications, the rescue failure rate, the incision infection rate, and the average length of the hospital stay (all $\mathrm{P}<0.05$ ), and the factors related to a decrease in inpatient satisfaction were increased postoperative 30-day mortality, a high incidence of major and minor complications, a high rescue failure rate, and a high incision infection rate.

Conclusions: There was a significant correlation between inpatient satisfaction and surgical quality evaluation indicators (i.e., 30-day mortality, major and minor complications, the rescue failure rate, the incision infection rate, and the average length of the hospital stay).

Keywords: Inpatient satisfaction; inpatients; surgery; quality indicators

Submitted Mar 16, 2021. Accepted for publication May 20, 2021.

doi: $10.21037 /$ gs-21-289

View this article at: http://dx.doi.org/10.21037/gs-21-289 


\section{Introduction}

Patient satisfaction is defined as "the response of health care recipients to the relevant content, processes, and outcomes of their service experience" (1). With the advancement of the reform of the national medical and health system, patient satisfaction questionnaires have become new tools for evaluating the service quality of medical service institutions (2). Under the notice of the medical service action plan [2018-2020] issued by the National Health and Family Planning Commission, patient satisfaction is an important indicator for measuring the service quality of medical and nursing services $(3,4)$. As the notice states, "The patient satisfaction evaluation is included in the comprehensive performance evaluation of medical and bealth institutions as an important indicator and used as the evaluation to improve the implementation effect of the medical service action plan." $(3,4)$.

The satisfaction of inpatients with the quality of medical services is also particularly important (5). Surgical departments have one of the highest number of inpatient admissions of hospital departments, and the satisfaction of surgical patients largely reflects the overall quality of hospitals (6). An increasing number of surgical procedures monitor the quality of their services through patient satisfaction measures (7). To determine whether the needs of patients have been met, this study examined 10 tertiary A hospitals in Chongqing to analyze the factors affecting the satisfaction of inpatients, and to explore the relationship between the satisfaction of inpatients and surgical evaluation indicators. Hospitals can use the results to improve the quality of comprehensive surgery, and thus improve the satisfaction of inpatients.

We present the following article in accordance with the SURGE reporting checklist (available at http://dx.doi. org/10.21037/gs-21-289).

\section{Methods}

\section{Study subjects}

In this study, based on Chongqing's medical service architecture and distribution, 10 tertiary A hospitals in Chongqing were selected as the study units using a stratified sampling principle, and 5,000 hospitalized surgical patients at these hospitals were randomly selected as the study subjects. To be eligible to participate in this study, patients had to meet the following inclusion criteria: (I) have been hospitalized for more than 3 days; (II) be in a stable condition; and (III) they had to be willing to participate in the questionnaire, and sign the Informed Consent Form. A total of 5,000 questionnaires were randomly distributed, and 4,665 valid questionnaires were returned; thus, there was a response rate of $93.3 \%$. Figure 1 shows the flow chart of study subject deletion and selection. All procedures performed in this study involving human participants were in accordance with the Declaration of Helsinki (as revised in 2013). The study was approved by ethics board of Army Medical University (No.: IRB-2019-12) and informed consent was taken from all the patients.

\section{Investigation and analysis methods}

A questionnaire on inpatient satisfaction, which had been developed by our team in a previous self-study, was used and distributed to the 10 selected tertiary A hospitals to conduct an on-site questionnaire with hospitalized surgical patients, who were asked to complete the questionnaire. The questionnaire comprised two parts: (I) a general data part; and (II) the inpatient satisfaction part. Part 1 gathered data about the general situation of inpatients, including data about gender, age, marital status, education level, occupation, monthly income, hospitalization costs, and payment methods. Part 2 gathered data about inpatients' satisfaction, including data about inpatients' satisfaction with the medical environment, medical facilities, logistics services of the ward, medical technology, service attitude, doctor-patient communication, medical charges, medical ethics, and treatment effect. The satisfaction questionnaire developed in this study used a 5 -point "Likert scale" $(8,9)$ (on which $1=$ very dissatisfied, $2=$ dissatisfied, $3=$ neutral, $4=$ satisfied $5=$ very satisfied). For statistical convenience, "very satisfied" and "satisfied" were combined into "satisfied" (mean score $\geq 4$ points)" and "neutral", "dissatisfied" and "very dissatisfied" were combined into "dissatisfied" (mean score $<4$ points). To ensure the quality of the questionnaire, the investigators who attended each of the hospitals received systematic training, distributed the questionnaire immediately, collected the questionnaire immediately after its completion, and answered questions on the spot.

The primary variables of this study were divided into three categories: (I) the demographic and sociological characteristics of inpatients; (II) hospitalization perceptions; and (III) the quality of surgery. The quality of surgery mainly related to 30-day postoperative mortality, major and minor complications, the rescue failure rate, readmission, 


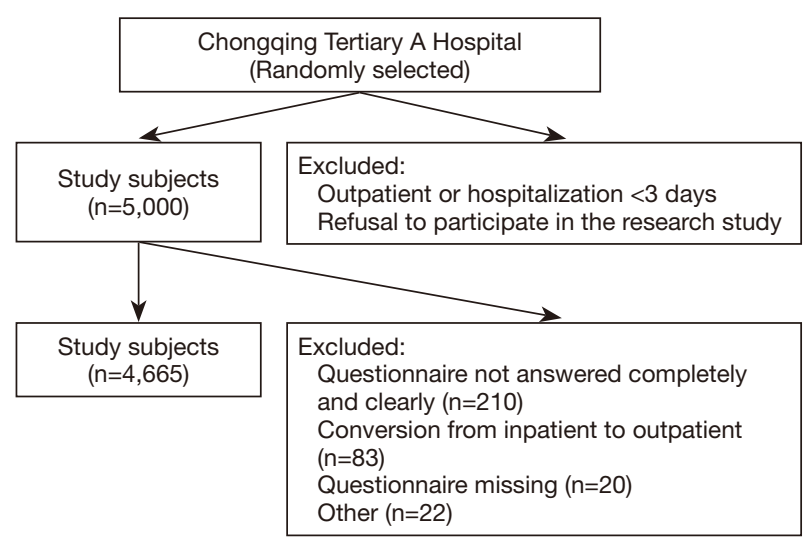

Figure 1 Study subject selection flow chart.

and the incision infection rate.

\section{Statistical analysis}

SPSS 19.0 statistical software was used for the data entry and analysis. The enumeration data were expressed as a (\%). A univariate analysis of patients' demographic sociological characteristics, hospitalization perceptions and the effects of the surgical quality on overall satisfaction was undertaken using a chi-square test. A multivariate analysis of the factors affecting satisfaction was undertaken via a logistic regression analysis. A $\mathrm{P}<0.05$ was considered statistically significant.

\section{Results}

\section{General data}

The basic characteristics of the general data of the hospitalized surgical patients in the investigated areas were analyzed (see Table 1). The results showed that $2,556(54.79 \%)$ patients were male and 2,109 (45.21\%) were female. In relation to age, $12.58 \%$ of the patients were $<18$ years old, and $64.78 \%$ were $18-60$ years old; thus, the latter age group accounted for a relatively high proportion of patients. The proportion of inpatients with a monthly family income of $<1,000 \mathrm{RMB}, 1,000-3,000 \mathrm{RMB}$, $3,000-5,000 \mathrm{RMB}$, and $>5,000 \mathrm{RMB}$ was $7.80 \%, 39.70 \%$, $24.97 \%$, and $27.52 \%$, respectively. In terms of the source of hospitalization costs, medical insurance accounted for the highest proportion $(35.67 \%)$, followed by commercial insurance $(23.21 \%)$, rural cooperative medical care
Table 1 General data of inpatients at 10 tertiary A hospitals in Chongqing

\begin{tabular}{|c|c|c|}
\hline Item & Number $(\mathrm{N})$ & Percent $(\%)$ \\
\hline \multicolumn{3}{|l|}{ Sex } \\
\hline Male & 2,556 & 54.79 \\
\hline Female & 2,109 & 45.21 \\
\hline \multicolumn{3}{|l|}{ Age (years) } \\
\hline$<18$ & 587 & 12.58 \\
\hline $18-60$ & 3,022 & 64.78 \\
\hline $60+$ & 1,056 & 22.64 \\
\hline \multicolumn{3}{|l|}{ Marital status } \\
\hline Unmarried & 1,073 & 23.00 \\
\hline Married & 2,101 & 45.04 \\
\hline Widowed & 316 & 6.77 \\
\hline Divorce & 1,175 & 25.19 \\
\hline \multicolumn{3}{|l|}{ Education level } \\
\hline Junior high school and below & 1,804 & 38.67 \\
\hline High school or specialty & 1,969 & 42.21 \\
\hline Bachelor degree or above & 892 & 19.12 \\
\hline \multicolumn{3}{|l|}{ Occupation } \\
\hline Public position & 559 & 11.98 \\
\hline Enterprise & 1,302 & 27.92 \\
\hline Farmer & 1,359 & 29.14 \\
\hline Worker & 1,005 & 21.54 \\
\hline Individual & 212 & 4.54 \\
\hline Other & 228 & 4.89 \\
\hline \multicolumn{3}{|l|}{ Monthly household income } \\
\hline$<1,000 \mathrm{RMB}$ & 364 & 7.80 \\
\hline 1,000-3,000 RMB & 1,852 & 39.70 \\
\hline $3,000-5,000 \mathrm{RMB}$ & 1,165 & 24.97 \\
\hline$>5,000 \mathrm{RMB}$ & 1,284 & 27.52 \\
\hline \multicolumn{3}{|l|}{ Sources of hospital costs } \\
\hline Rural cooperation & 989 & 21.20 \\
\hline Medicare & 1,664 & 35.67 \\
\hline Commercial Insurance & 1,083 & 23.21 \\
\hline Completely self-paid & 658 & 14.11 \\
\hline Other sources & 271 & 5.81 \\
\hline
\end{tabular}


Table 2 Questionnaire results of overall satisfaction of inpatients and satisfaction in all dimensions

\begin{tabular}{lccc}
\hline Satisfaction & Satisfied, n (\%) & Dissatisfied, n (\%) & P value \\
\hline Overall satisfaction & $4,138(88.7)$ & $527(11.3)$ & $630(13.5)$ \\
Medical environment & $4,035(86.5)$ & $504(10.8)$ & 0.001 \\
Medical facilities & $4,161(89.2)$ & $448(9.6)$ & 0.448 \\
Ward logistics services & $4,217(90.4)$ & $406(8.7)$ & 0.008 \\
Medical technology & $4,259(91.3)$ & $518(11.1)$ & 0.768 \\
Service attitude & $4,147(88.9)$ & $686(14.7)$ & 0.000 \\
Doctor-patient communication & $3,979(85.3)$ & $490(10.5)$ & 0.219 \\
Medical charges & $4,175(89.5)$ & \\
\hline
\end{tabular}

$P$ value refers to the statistical significance of satisfaction for each dimension and overall satisfaction.

(21.20\%), complete self-pay (14.11\%), and other sources $(5.81 \%)$.

\section{Analysis of inpatient satisfaction}

\section{Overall satisfaction and satisfaction across all dimensions}

Table 2 shows the results of inpatients' overall satisfaction and satisfaction across all dimensions. From the results, it can be seen that the overall satisfaction rate was relatively high $(88.7 \%)$. A comparison of the satisfaction results across all dimensions, showed that inpatients' level of satisfaction with medical technology and ward logistics services was high (more than 90\%), while inpatients' level of satisfaction with doctor-patient communication was relatively low $(85.3 \%)$.

\section{Analysis of factors affecting inpatient satisfaction Satisfaction of inpatients with different demographic and sociological characteristics}

Of the inpatients sampled at the 10 hospitals in this study, there was no significant differences among the basic demographic characteristics in relation to gender and occupation; however, there were significant differences in relation to age $\left(\chi^{2}=44.678, P=0.000\right)$, marital status $\left(\chi^{2}=41.929, \mathrm{P}=0.000\right)$, education level $\left(\chi^{2}=39.570, \mathrm{P}=0.000\right)$, monthly family income $\left(\chi^{2}=25.584, \mathrm{P}=0.000\right)$, source of medical costs $\left(\chi^{2}=44.970, \mathrm{P}=0.000\right)$, the average length of the hospital stay $\left(\chi^{2}=373.415, \mathrm{P}=0.000\right)$, and first hospital admission $\left(\chi^{2}=278.048, \mathrm{P}=0.000\right)$ (see Table 3).

\section{Inpatient satisfaction with perceptions hospitalization}

There was no significant difference in the perceptions of hospitalization in terms of medical environment, medical facilities and ward logistics services; however, there were significant differences in the perceptions of hospitalization in terms of doctor-patient communication $\left(\chi^{2}=12.537\right.$, $\mathrm{P}=0.000)$, surgical quality $\left(\chi^{2}=17.409, \mathrm{P}=0.000\right)$, and service attitude $\left(\chi^{2}=16.482, \mathrm{P}=0.000\right)$ (see Table 4$)$.

\section{Relationship between inpatient satisfaction and surgical} quality indicators

In relation to the relationship between inpatient satisfaction and surgical quality indicators, there were significant differences in 30-day postoperative mortality, major and minor complications, the rescue failure rate, the readmission rate, and the incision infection rate (all $\mathrm{P}=0.000$; see Table 5).

\section{Logistic regression analysis of inpatient satisfaction}

The overall satisfaction of inpatients was divided into binary dependent variables, such that "very dissatisfied," "dissatisfied," and "general" were set as 1 , and comprised the dissatisfied group, and "satisfied" and "very satisfied" were set as 2, and comprised the satisfied group. A univariate analysis was undertaken to examine inpatient satisfaction in relation to inpatients' demographic sociological characteristics, hospitalization perceptions and the quality of surgery. 15 factors thought to affect overall inpatient satisfaction were used as independent variables, and defined and assigned values (see Table 6). A binary logistic regression analysis was also performed, the results of which are set out in Table 7 .

As Table 7 shows, a variable with a level of $\mathrm{P}=0.05$ was selected as the main influencing factor of the regression equation, and independent variables with a $\mathrm{P}>0.05$ were excluded. 10 variables entered the regression equation. The logistic regression resulted in the following equation: $\mathrm{Y}=$ 
Table 3 Relationship between inpatient satisfaction and characteristic data

\begin{tabular}{|c|c|c|c|c|c|c|}
\hline \multirow{2}{*}{ Variable } & \multicolumn{2}{|c|}{ Satisfied } & \multicolumn{2}{|c|}{ Not satisfied } & \multirow{2}{*}{$\chi^{2}$} & \multirow{2}{*}{$\mathrm{P}$} \\
\hline & $\mathrm{N}$ & $\%$ & $\mathrm{~N}$ & $\%$ & & \\
\hline Sex & & & & & 3.190 & 0.074 \\
\hline Female & 1,009 & 47.84 & 1,100 & 52.16 & & \\
\hline Age (years) & & & & & 44.678 & 0.000 \\
\hline $18-60$ & 1,436 & 47.52 & 1,586 & 52.48 & & \\
\hline $60+$ & 610 & 57.77 & 446 & 42.23 & & \\
\hline Marital status & & & & & 41.929 & 0.000 \\
\hline Unmarried & 529 & 49.30 & 544 & 50.70 & & \\
\hline Education level & & & & & 39.570 & 0.000 \\
\hline Junior high school and below & 1,046 & 57.98 & 740 & 41.02 & & \\
\hline High school or specialty & 971 & 49.31 & 998 & 50.69 & & \\
\hline Bachelor degree or above & 434 & 48.65 & 458 & 51.35 & & \\
\hline Occupation & & & & & 7.139 & 0.210 \\
\hline Public position & 286 & 51.16 & 273 & 48.84 & & \\
\hline Enterprise & 692 & 53.15 & 610 & 46.85 & & \\
\hline Farmer & 768 & 56.51 & 591 & 43.49 & & \\
\hline $3,000-5,000 \mathrm{RMB}$ & 645 & 55.36 & 520 & 44.64 & & \\
\hline$>5,000 \mathrm{RMB}$ & 681 & 53.04 & 603 & 46.96 & & \\
\hline Sources of hospital costs & & & & & 44.970 & 0.000 \\
\hline Rural cooperation & 470 & 47.52 & 519 & 52.48 & & \\
\hline Medicare & 944 & 56.73 & 720 & 43.27 & & \\
\hline Commercial insurance & 527 & 48.66 & 556 & 51.34 & & \\
\hline Completely self-paid & 284 & 43.16 & 374 & 56.84 & & \\
\hline Other sources & 138 & 50.92 & 133 & 49.08 & & \\
\hline Average length of stay (days) & & & & & 373.415 & 0.000 \\
\hline$\leq 7$ & 1,812 & 84.99 & 320 & 15.01 & & \\
\hline$>7$ & 1,500 & 59.22 & 1,033 & 40.78 & & \\
\hline First admission or not & & & & & 278.048 & 0.000 \\
\hline Yes & 1,746 & 72.12 & 675 & 27.88 & & \\
\hline No & 2,046 & 91.18 & 198 & 8.82 & & \\
\hline
\end{tabular}


Table 4 Relationship between perception of hospitalization and patient satisfaction

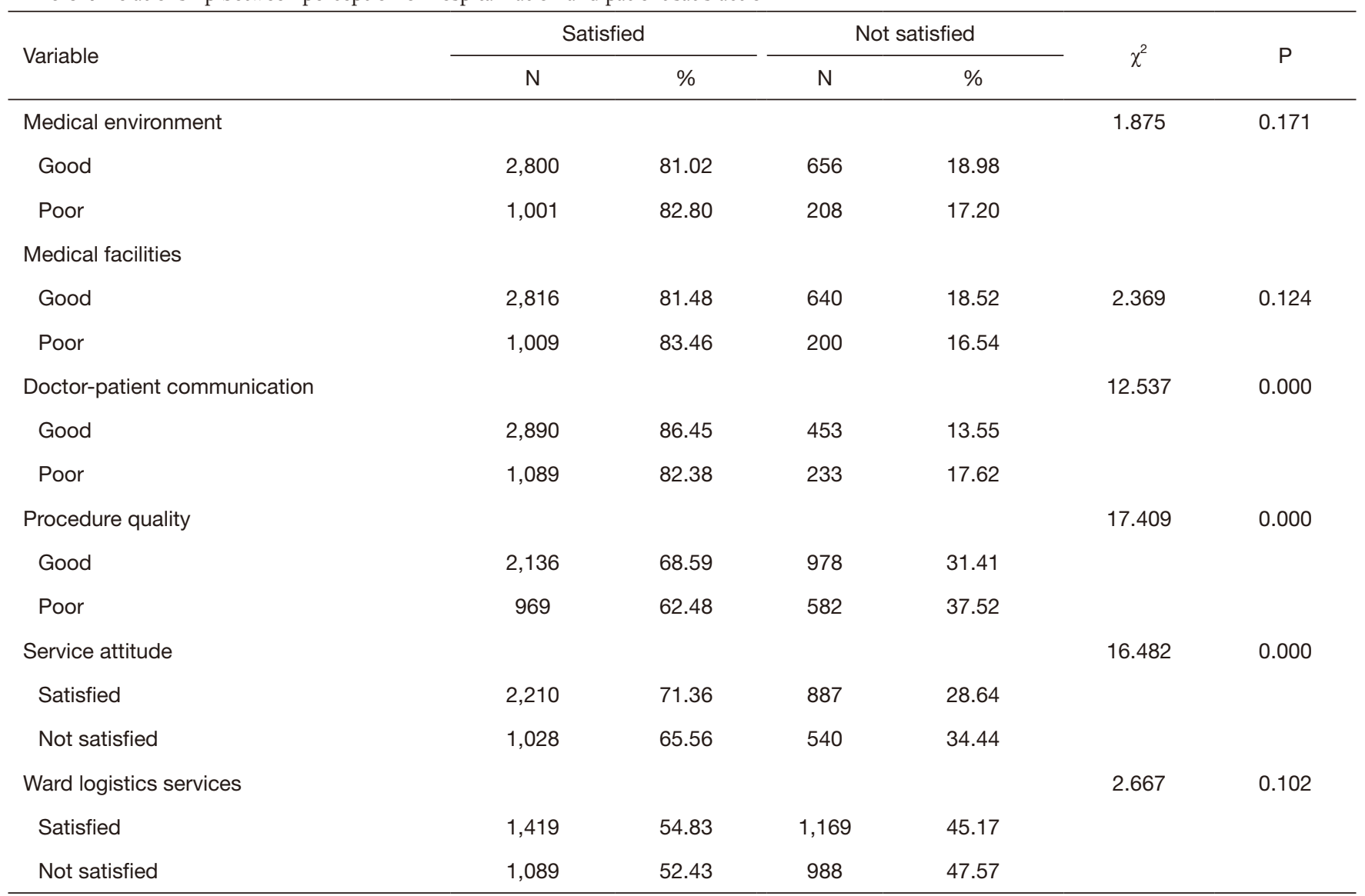

$2.732+0.614 \mathrm{X} 1-0.53 \mathrm{X} 2-2.126 \mathrm{X} 6+1.207 \mathrm{X} 7+1.542 \mathrm{X} 9$ $+1.036 \mathrm{X} 10-1.548 \mathrm{X} 11-1.047 \mathrm{X} 12-1.245 \mathrm{X} 13-1.327 \mathrm{X} 15$. Based on the regression coefficients of the independent variables in Table 7 , it can be concluded that the main factors affecting inpatient satisfaction were the average length of the hospital stay (X6), postoperative 30-day mortality (X11), the quality of surgery (X9), the incision infection rate (X15), the rescue failure rate (X13), whether or not it was a first admission (X7), major and minor complications (X12), service attitude (X10), age (X1), and marital status (X2).

\section{Discussion}

Following the introduction of the patient-centered concept, questionnaires and studies on patient satisfaction have gradually increased both nationally and internationally (10-12). Notably, research on the relationship between the quality of surgery and patient satisfaction has attracted much attention (13-15); however, the relationship between inpatient satisfaction and the quality of surgery has not been closely examined (16). Surgery plays an important role in surgical treatment, and can cause related complications and even lead to death. Thus, the issue of how to improve the quality of surgery has become an important area of research in this field (17).

In this study, we administered a random sampling questionnaire to inpatients at 10 tertiary A care hospitals in Chongqing, and analyzed and compared the various factors affecting inpatient satisfaction, and the relationship between inpatient satisfaction and the quality of surgery. The results showed that inpatients had a high overall level of satisfaction with hospitalization $(88.7 \%)$, which is consistent with the high overall level of satisfaction (92.9\%) found in the study by Smith et al. (18). There were some links between the demographic sociological characteristics of inpatients, their perceptions of hospitalization, factors related to the quality of surgical procedures, and the satisfaction of inpatients in this study. A univariate analysis revealed significant 
Table 5 Quality of surgery and inpatient satisfaction

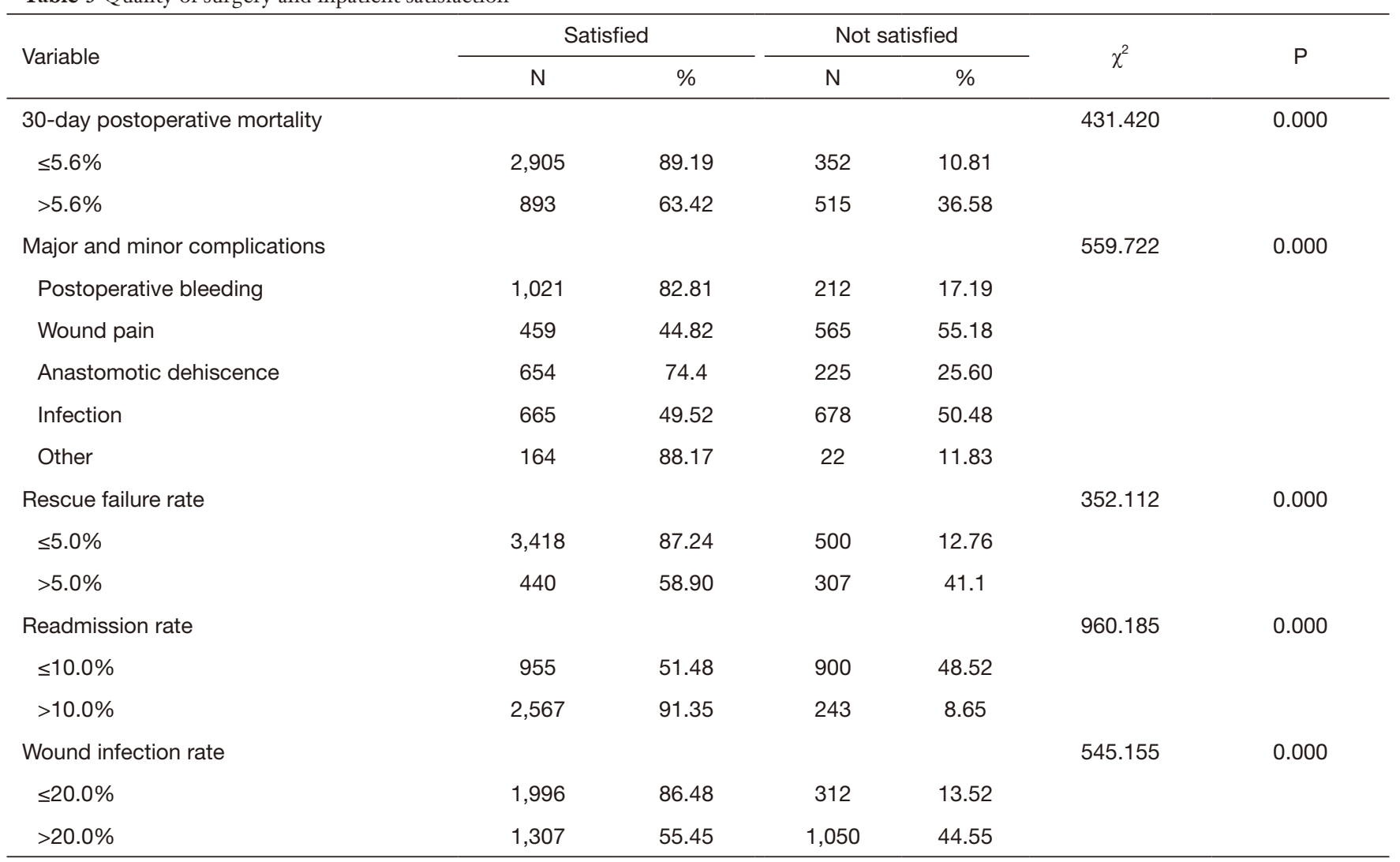

Table 6 Independent variable value assignment table

\begin{tabular}{|c|c|}
\hline Independent variable & Value assignment \\
\hline Marital status (X2) & $1=$ never married, $2=$ married, $3=$ widowed, $4=$ divorced \\
\hline Education level (X3) & $1=$ junior high school or below, $2=$ senior high school or specialist, $3=$ undergraduate or above \\
\hline Monthly household income (X4) & $1=<1,000 \mathrm{RMB}, 2=1,000-3,000 \mathrm{RMB}, 3=3,000-5,000 \mathrm{RMB}, 4=>5,000 \mathrm{RMB}$ \\
\hline Average hospital stays (X6) & $1=\leq 7$ days, $2=>7$ days \\
\hline First admission or not (X7) & $1=$ yes, $0=$ no \\
\hline Doctor-patient communication (X8) & $1=$ good, $2=$ poor \\
\hline Surgical quality (X9) & $1=$ good, $0=$ poor \\
\hline Major and minor complications (X12) & $1=$ postoperative bleeding, $2=$ wound pain, $3=$ anastomotic dehiscence, $4=$ infection, $5=$ other \\
\hline Rescue failure rate $(\mathrm{X} 13)$ & $1=\leq 5.0 \%, 2=>5.0 \%$ \\
\hline Readmission rate $(\mathrm{X} 14)$ & $1=\leq 10 \%, 2=>10 \%$ \\
\hline Wound infection rate (X15) & $1=\leq 20.0 \%, 2=>20.0 \%$ \\
\hline
\end{tabular}


Table 7 Regression analysis of factors affecting inpatient satisfaction

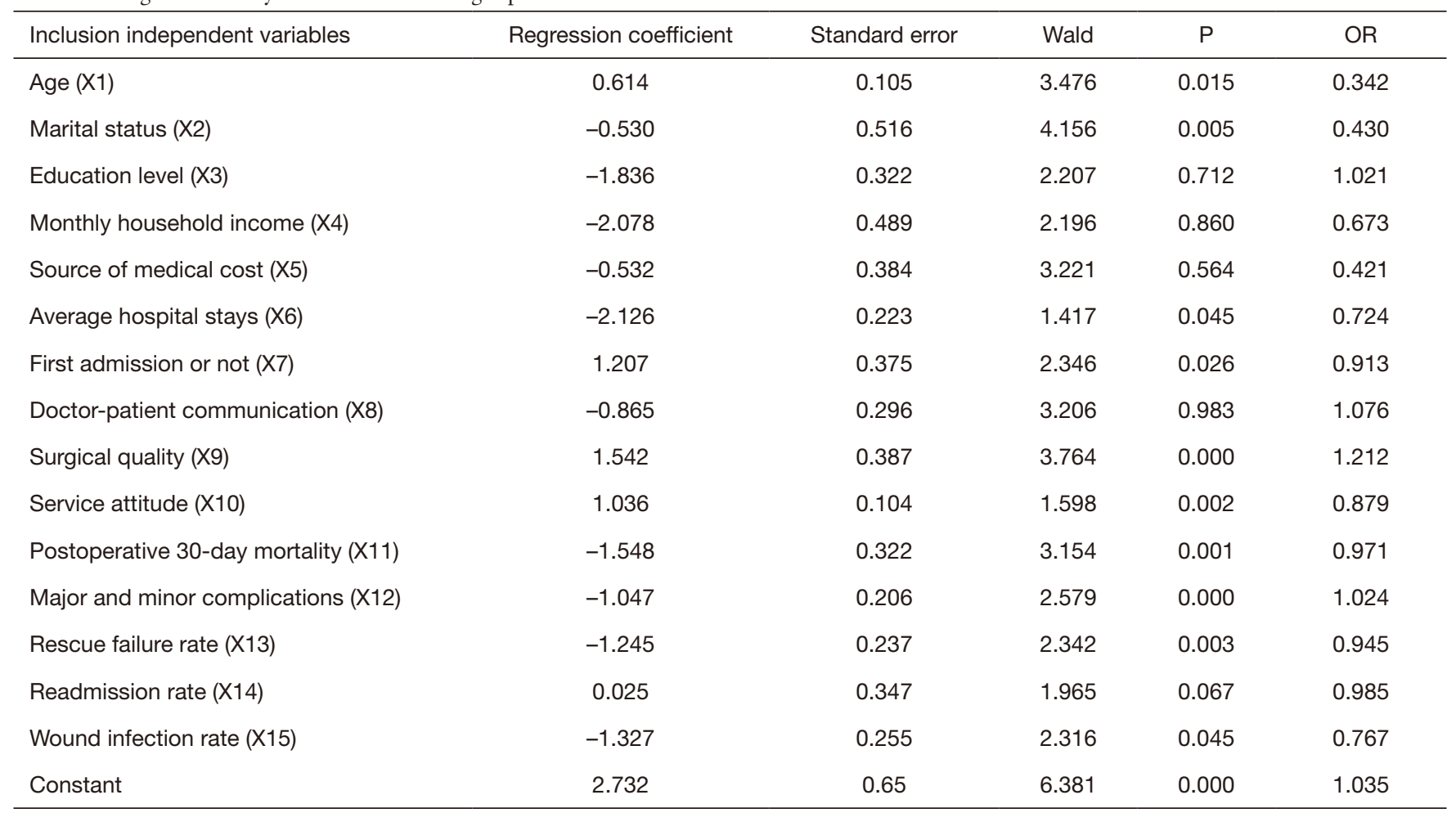

statistical differences in factors such as age, marital status, education level, family income, source of medical costs, the average length of the hospital stay, whether it was a patient's first admission or not, doctor-patient communication, the quality of surgery, service attitude, 30-day postoperative mortality, major and minor complications, the rescue failure rate, the readmission rate, and the incision infection rate.

The results of a logistic regression analysis indicated that the average length of the hospital stay, postoperative 30day mortality, the quality of surgery, the incision infection rate, the rescue failure rate, whether it was a patient's first admission or not, major and minor complications, service attitude, age, and marital status had some effect on inpatient satisfaction. Among these, related indicators affecting the quality of surgery (i.e., the average length of the hospital stay, postoperative 30-day mortality, the incision infection rate, the rescue failure rate, and major and minor complications) were found to play an important role in the satisfaction regression equation. Thus, consistent with Greg et al.'s findings (19) that there was no significant relationship between readmission rate and satisfaction, a close relationship was found between the quality of surgery and inpatient satisfaction. Unlike the present study, Sacks et al. did not find any significant relationship between satisfaction and major complications; however, Lobo Prabhu et al. found that 30-day readmission and patient satisfaction with complications were low (20). It should be noted that these findings may be related to other factors, such as different departments and differences in sample size.

A positive correlation was found between service attitude and patient satisfaction. Thus, hospitals should improve service attitudes and communication with patients to increase patient satisfaction. As Seleznev et al. observed, "patient satisfaction is a comprehensive embodiment of service performance of medical institutions and the service quality of medical institutions should be improved" (21). Consistent with the findings of Tehrani that older patients had higher levels of satisfaction than younger patients (22), a relationship was also found between inpatient satisfaction and basic characteristics, such as patient age and marital status. However, it should be noted that this is inconsistent with the findings of related studies (23), which have found low levels of satisfaction among patients older than 55 years.

Service attitude was also found to be a factor affecting the satisfaction of inpatients. Specifically, the results showed 
that the better the service attitude, the higher the level of patient satisfaction. This finding is consistent with Shan's observation that the trust of medical institutions should be increased, and doctor-patient relationships should be a priority (24).

This study has a number of limitations. First, the relationship between satisfaction and surgical quality was only studied in inpatients at 10 tertiary A hospitals in Chongqing. Second, the sample size may also have some limitations. Third, only the satisfaction of inpatients was examined; thus, no comparisons could be made in relation to inpatients and outpatients. Future studies will seek to address this issue.

In summary, this study investigated the satisfaction of 5,000 inpatients at 10 tertiary A hospitals in Chongqing, and found that $88.7 \%$ of inpatients were generally satisfied with the hospitals they were in. The analysis showed that 3 factors were related (i.e., demographic characteristics, hospitalization perceptions, and surgical quality), and that there was a certain relationship between inpatient satisfaction and above factors. Among these factors, the average length of the hospital stay, postoperative 30day mortality, major and minor complications, the rescue failure rate, and the incision infection rate in surgical quality indicators were particularly important in relation to patient satisfaction. Thus, hospitals should seek to improve surgical quality to increase the satisfaction of inpatients. The investigation and analysis of this paper provide some data on the relationship between inpatient satisfaction and surgical quality indicators, and could be used to improve the quality of medical and health institutions.

\section{Acknowledgments}

Funding: This work was supported by the Humanities and Social Sciences Fund Project of Army Medical University for The Analysis on the Mining and Implementation Path of Ideological and Political Elements in Professional Management Courses (2020XRW07).

\section{Footnote}

Reporting Checklist: The authors have completed the SURGE reporting checklist. Available at http://dx.doi. org/10.21037/gs-21-289

Data Sharing Statement: Available at http://dx.doi. org/10.21037/gs-21-289
Conflicts of Interest: All authors have completed the ICMJE uniform disclosure form (available at http://dx.doi. org/10.21037/gs-21-289). The authors have no conflicts of interest to declare.

Ethical Statement: The authors are accountable for all aspects of the work in ensuring that questions related to the accuracy or integrity of any part of the work are appropriately investigated and resolved. All procedures performed in this study involving human participants were in accordance with the Declaration of Helsinki (as revised in 2013). The study was approved by ethics board of Army Medical University (No.: IRB-2019-12) and informed consent was taken from all the patients.

Open Access Statement: This is an Open Access article distributed in accordance with the Creative Commons Attribution-NonCommercial-NoDerivs 4.0 International License (CC BY-NC-ND 4.0), which permits the noncommercial replication and distribution of the article with the strict proviso that no changes or edits are made and the original work is properly cited (including links to both the formal publication through the relevant DOI and the license). See: https://creativecommons.org/licenses/by-nc-nd/4.0/.

\section{References}

1. Pascoe GC. Patient satisfaction in primary health care: a literature review and analysis. Eval Program Plann 1983;6:185-210.

2. Huang $\mathrm{H}$, Chen $\mathrm{P}$, Chen Z. Progress in the research of hospital-patient relation satisfaction. Modern Hospital 2015.

3. Batbaatar E, Dorjdagva J, Luvsannyam A, et al. Determinants of patient satisfaction: a systematic review. Perspect Public Health 2017;137:89-101.

4. Jiang F, Hu L, Zhao R, et al. Satisfaction of family members with inpatient psychiatric care and its correlates: a national survey in China. BMC Psychiatry 2019;19:427.

5. Feldman SF, Lapidus N, Cosnes J, et al. Comparing Inpatient Satisfaction Collected via a Web-Based Questionnaire Self-Completion and Through a Telephone Interview: An Ancillary Study of the SENTIPAT Randomized Controlled Trial. J Med Internet Res 2017;19:e293.

6. Weiser TG, Haynes AB, Molina G, et al. Estimate of the global volume of surgery in 2012: an assessment supporting improved health outcomes. Lancet 2015;385 
Suppl 2:S11.

7. Ray GS, Ekelund P, Nemes S, et al. Changes in healthrelated quality of life are associated with patient satisfaction following total hip replacement: an analysis of 69,083 patients in the Swedish Hip Arthroplasty Register. Acta Orthop 2020;91:48-52.

8. Beadle KL, Helbling AR, Love SL, et al. Isopropyl Alcohol Nasal Inhalation for Nausea in the Emergency Department: A Randomized Controlled Trial. Ann Emerg Med 2016;68:1-9.e1.

9. Hendriks AA, Vrielink MR, van Es SQ, et al. Assessing inpatients' satisfaction with hospital care: should we prefer evaluation or satisfaction ratings? Patient Educ Couns 2004;55:142-6.

10. Voutilainen A, Pitkäaho T, Kvist T, et al. How to ask about patient satisfaction? The visual analogue scale is less vulnerable to confounding factors and ceiling effect than a symmetric Likert scale. J Adv Nurs 2016;72:946-57.

11. Korkmaz T, Balaban B, Onder H, et al. The effect of patient qualifications and number of patient accompanist on patient's satisfaction. Turk J Emerg Med 2016;16:93-7.

12. Berning V, Laupheimer $M$, Nübling $M$, et al. Influence of quality of recovery on patient satisfaction with anaesthesia and surgery: a prospective observational cohort study. Anaesthesia 2017;72:1088-96.

13. Shyr BU, Shyr BS, Chen SC, et al. Operative results and patient satisfaction after robotic pancreaticoduodenectomy. Asian J Surg 2020;43:519-25.

14. Barlési F, Boyer L, Doddoli C, et al. The place of patient satisfaction in quality assessment of lung cancer thoracic surgery. Chest 2005;128:3475-81.

15. Tevis SE, Kennedy GD, Kent KC. Is There a Relationship Between Patient Satisfaction and Favorable Surgical Outcomes? Adv Surg 2015;49:221-33.

16. Lyu H, Wick EC, Housman M, et al. Patient satisfaction

Cite this article as: Shang R, Wang D, Cai H, Chen J, Lv L, Huang C. Relationship between inpatient satisfaction and the quality of surgery. Gland Surg 2021;10(5):1726-1735. doi: 10.21037/gs-21-289 as a possible indicator of quality surgical care. JAMA Surg 2013;148:362-7.

17. Alidina S, Kuchukhidze S, Menon G, et al. Effectiveness of a multicomponent safe surgery intervention on improving surgical quality in Tanzania's Lake Zone: protocol for a quasi-experimental study. BMJ Open 2019;9:e031800.

18. Smith WR, Wera J, Ramsey FV, et al. Patient Satisfaction in the Preoperative Period: Preparing for Hand Surgery. Hand (N Y) 2019;14:646-50.

19. Sacks GD, Lawson EH, Dawes AJ, et al. Relationship between hospital performance on a patient satisfaction survey and surgical quality. JAMA Surg 2015;150:858-64.

20. Lobo Prabhu K, Cleghorn MC, Elnahas A, et al. Is quality important to our patients? The relationship between surgical outcomes and patient satisfaction. BMJ Qual Saf 2018;27:48-52.

21. Seleznev I, Alibekova R, Clementi A. Patient satisfaction in Kazakhstan: Looking through the prism of patient healthcare experience. Patient Educ Couns 2020;103:2368-72.

22. Tehrani A, Feldman S, Camacho F, et al. Patient Satisfaction with Outpatient Medical Care in the United States. Health Outcomes Research in Medicine 2011;2:e197-e202.

23. Pozdnyakova A, Tung A, Dutton R, et al. Factors affecting patient satisfaction with their anesthesiologist: an analysis of 51,676 surveys from a large multihospital practice. Anesth Analg 2019;129:951-9.

24. Shan L, Li Y, Ding D, et al. Patient Satisfaction with Hospital Inpatient Care: Effects of Trust, Medical Insurance and Perceived Quality of Care. PLoS One 2016;11:e0164366.

(English Language Editor: L. Huleatt) 